\title{
Diagnostic Dilemma of Subcuteneous Basidiobolomycosis: A Clinicomycological Study
}

\author{
Pal Nupur ${ }^{1}$, Pal Sangeeta ${ }^{1}$, Pal Sayan ${ }^{1}$, Kalidas Rit $^{1 *}$, \\ Maiti K. Prasanta ${ }^{1,3}$ and Chatterjee Gobinda ${ }^{2}$
}

${ }^{1}$ Department of Microbiology, ${ }^{2}$ Department of Dermatology, Institute of Post-Graduate

Medical Education \& Research, 244 AJC Bose Road, Kolkata-700020, India

${ }^{3}$ Department of Mycology, School of Tropical Medicine, 108 C.R. Ave., Kolkata -73, India

*Corresponding author

\section{Keywords \\ Basidiobolomycosis, Diagnostic dilemma, $\mathrm{KOH}$ microscopy, Oral SSKI therapy \\ Article Info \\ Accepted: \\ 17 May 2019 \\ Available Online: \\ 10 June 2019}

\section{A B S T R A C T}

Basidiobolomycosis is a very rare form of subcutaneous mycosis often confused with other clinically mimicking conditions. Poor clinical suspicion and lack of experience due to its rarity sometimes misdirects clinicians, pathologists and microbiologists. Wrongful diagnosis may lead to inappropriate and fatal interventions. This present endeavour is aimed at a thorough study of those cases to readdress the challenges in diagnosis and management from eastern India. The study is to create a database of proved cases of basidiobolomycosis from clinically mimicking conditions and to create awareness regarding diagnostic dilemma of these cases. Sixty three clinically suspected cases were included in this study. Among those twenty eight were prospective cases and thirty five were retrospective cases. Relevant histories were taken. Apart from routine hematological, biochemical and radiological investigations, exisional biopsy materials from subcutaneous swelling was examined by direct microscopy with $\mathrm{KOH}$ wet mount and fungal culture. Histopatholgical examination was also done. Any fungal growth was identified by growth characteristics and morphological features. Four prospective cases and seven retrospective confirmed cases of subcutaneous basidiobolomycosis were detected from sixty three clinically suspected patients. Out of them eight were found to be culture positive by repeated attempt. In all cases provisional diagnosis could be made by direct $\mathrm{KOH}$ microscopy and treatment with oral saturated solution of potassium iodide were initiated with or without positive fungal growth and HPE report. Histopathological sensitivity was low (54.5\%). Three clinically and histopathologically suspected cases of rabdomyosarcoma were diagnosed as subcutaneous basidiobolomycosis in this study. Unfortunately one case was lost on follow up. Rest cases were followed up for at least six months post treatment and all showed good response in therapy. A database comprising diagnostic and therapeutic clues has been proposed for these rare subcutaneous mycoses. . With high degree of clinical suspiscion, responsiveness of emperical oral SSKI therapy can be a reliable diagnostic clue. 


\section{Introduction}

Basidiobolomycosis is an uncommon chronic subcutaneous phycomycosis presented as a localised nonmetastatic rapidly progressive firm, painless swelling of subcuteneous tissue usually involving immunocompetent younger age groups, caused by the fungus Basidiobolus ranarum. Basidiobolus ranarum belonging to the class zygomycetes and order entomophthorales was first described as an isolate from frogs in 1886 by Eidam. ${ }^{[1]}$ Human cases of entomopthoromycosis can be of 4 types, subcuteneous phycomycosis caused by Basidiobolus ranarum, chronic rhinofacial phycomycosis caused by Conidiobolus coronatus, gastrointestinal basidiobolomycosis and disseminated basidiobolomycosis. ${ }^{[2,3,4]}$ Diagnosis is confirmed either by demonstration of typical broad fungal hyphae surrounded by radiating, intensely eosinophilic granular material (splender hoeppli phenomenon) on hisopathological examination of tissue or / and by isolation and identification of fungal elements by culture.

Diagnosis is often delayed or misdirected due to poor degree of clinical suspicions or confusions with many similar looking conditions. Laboratory confirmations often become difficult due to improper sample collection, inadequate examinations of tissue with scanty fungal bodies or confusion with similar looking structures and failure to grow in culture media. In such a situation, thorough and repeated investigations by expert clinicians and microbiologists can only reflect the exact magnitude of the problem.

This clinicomycological study conducted for the purpose to create a database of mycologically confirmed subcuteneous basidiobolomycosis with special emphasis on diagnostic dillema.

\section{Materials and Methods}

The clinicomycological study included both prospective and retrospective data. It had been conducted for a period of 5 years (2013-2018) and 10 years (1991-2001) in the microbiology department of two institutions in eastern India respectively. 28 prospective cases and 35 retrospective cases were included in the study. Clinically suspected basidiobolomycosis case was considered those cases presented with chronic progressive subcuteneous swelling among immunocompetetent younger age groups without any systemic manifestations. Out of all these basidiobolomycosis were concluded either by demonstration of typical splender-hoeppli bodies surrounding broad sparsely septate or aseptate fungal bodies and/or isolation and identification of characteristically beaked zygospores from culture. Demonstration of typical broad fungal hyphae from direct $\mathrm{KOH}$ microscopy was also included as provisional diagnosis in this study. History of the suspected patients were taken in details relevant to their present conditions, e.g. residence, occupation, history of trauma, insect bite, duration of the lesions, nature of progression, regression if any, associated clinical symptoms like fever, pain, discharge of any fluid, grains etc, Queries regarding immune status, history of antimicrobial or other drug therapy were also made accordingly. Clinical examination, routine blood and radiological investigations were reviewed thoroughly.The excisional punch biopsy specimen taken from the advancing edges of the swelling was received by the mycology department. Each sample was minced aseptically and one portion was subjected to direct microscopic examination with $10 \% \mathrm{KOH}$, Others were inoculated onto several slants of the Sabouraud's dextrose agar with cycloheximide and/ or chloramphenicol. Tubes were incubated at $25^{\circ} \mathrm{C}$ in BOD incubator for 4-6 weeks with periodic inspection for evidence of fungal 
growth. Once the growth appeared in the slant, the fungal colonies were observed from both obverse and the reverse side. Identification was done based on finding of colony morphology of fungi, $\mathrm{KOH}$ wet mount examination, Lactophenol cotton blue (LPCB) tease mount to see their morphology which had been finally supported by slide culture study. Another portion of tissue was sent for histopathological examination with haematoxyline\&eosine stain or special fungal stain like periodic acid scieff (PAS) or Gomoris methamine silver (GMS).

In retrospective cases all outpatient medical records were reviewed, and data were collected about symptoms, medical and social history, laboratory and radiological examinations, procedures, treatment, and outcome.

\section{Results and Discussion}

Out of total 63 clinically suspected basidiobolomycosis cases eleven cases, four cases from prospective study and seven from retrospective cases were confirmed as basidiobolomycosis either histopathologically or by $\mathrm{KOH}$ microscopy and culture. Hence, confirmed cases of basidiobolomycosis are eleven out of 63 suspected cases $(17 \%)$ in 15 years. Nine out of eleven cases were below twenty years age with male \& female ratio 1:3. (Table1, figure1) All patients were otherwise healthy without any evidence of immunodeficiency. Two patients had above 20 years age group and two patients had swelling at unusual sites left upper abdomen and left arm. By $\mathrm{KOH}$ microscopy typical broad fungal elements were detected in all cases and eight out of eleven cases $(72.7 \%)$ were confirmed by repeated culture, Macroscopically on Sabouraud agar, colonies had a waxy, yellowish-to-gray appearance with many radial folds (figure $2 a \& 2 c$ ). On microscopic examination of LPCB smear, $B$. ranarum identified by characteristically paired beaked zygospores (figure2d). But histopathologically sensitivity was not satisfactory. Only in six $(54.5 \%)$ patients histpathologically possible diagnosis of basidiobolomycosis were made by evaluating some typical features including anatomic site, state of the mucosal lining, granulomatous inflammation, tissue eosinophilia, necrosis, fungal elements consistent with zygomycosis, and structures showing Splendore-Hoeppli bodies.(figure $2 \mathrm{~b}$ ). Most of the cases were reported from five districts in and around Kolkata except one case came from Malda and one from Agartala ,Tripura. All patient were treated sucessfully with oral saturated solution of potassium iodide (SSKI) until the clinical resolution, except one child who was lost on follow up and later it was found that he had been treated outside as rabdomycosarcoma with surgical excision of buttok mass. Twenty of rest 24 prospective cases were concluded as various other conditions viz. mycetoma (5 cases, 18\%), Lupus vulgaris (2 cases,7\%), Atypical mycobacterial infections (3 cases; 10\%), soft tissue tumor $(3,10 \%)$, fileria $(1 ; 5 \%)$; hypertrophic discoid lupus erthrematosus (2 cases, $7 \%$ ) fixed cutaneous sporothricosis (2, $7 \%$ ), cuteneous zygomycosis $(2,7 \%)$, four cases were lost in follow up. Unfortunately, retrospective cases data could not be found for diagnosis of other conditions.

Basidiobolomycosis is a very rare form of subcutaneous zygomycetes presented as a subcuteneous granuloma mainly in the lower part of the body like perineum, buttocks, trunk and thighs of immunocompetent hosts, primarily children and young adults without any features of angioinvasion. Unlike other zygomycosis the presenting clinical feature is a firm subcutaneous painless indurated swelling on lower extremity and buttock that gradually enlarges peripherally into a clearly defined flat mass attached to the overlying skin. 
Table.1 Summary of the findings of the confirmed Basidiobolomycosis cases

\begin{tabular}{|c|c|c|c|c|c|c|c|c|}
\hline $\begin{array}{l}\text { Age } \\
/ \text { sex }\end{array}$ & Location & $\begin{array}{c}\text { Clinical } \\
\text { diagnosis }\end{array}$ & Residence & $\begin{array}{c}\text { KOH } \\
\text { (No of } \\
\text { attempt) }\end{array}$ & $\begin{array}{c}\text { HPE } \\
\text { (No of } \\
\text { attempt) }\end{array}$ & $\begin{array}{l}\text { Culture } \\
\text { (No of } \\
\text { attempt) }\end{array}$ & $\begin{array}{c}\text { Treatme } \\
\text { nt }\end{array}$ & $\begin{array}{l}\text { Response to } \\
\text { treatment }\end{array}$ \\
\hline $18 / \mathrm{F}$ & Lt. Thigh & - & Nadia & $2^{\text {nd }}$ & ND & $2^{\text {nd }}$ & oralSSKI & Good response \\
\hline $13 / F$ & Rt.arm & - & Howrah & $1^{\text {st }}$ & ND & $2^{\text {nd }}$ & oralSSKI & $\begin{array}{l}\text { Moderate to good } \\
\text { improvement }\end{array}$ \\
\hline $2.5 / \mathrm{F}$ & $\begin{array}{l}\text { Lt.Upper } \\
\text { abdomen }\end{array}$ & $\begin{array}{l}\text { Soft tissue } \\
\text { tumor }\end{array}$ & 24-Pgs (N) & $1^{\text {st }}$ & ND & $1^{\text {st }}$ & oralSSKI & $\begin{array}{l}\text { Moderate } \\
\text { Improvement }\end{array}$ \\
\hline $\begin{array}{l}1.5 / \\
M\end{array}$ & Buttock & $\begin{array}{l}\text { Soft tissue } \\
\text { tumor }\end{array}$ & Kolkata & $1^{\text {st }}$ & $1^{\text {st }}$ & $1^{\text {st }}$ & oralSSKI & Lost on follow up \\
\hline $\begin{array}{l}2.5 / \\
\mathrm{M}\end{array}$ & $\begin{array}{l}\text { Rt.buttock } \\
\text { \& thigh }\end{array}$ & - & 24-Pgs (N) & $1^{\text {st }}$ & $1^{\text {st }}$ & NG & oralSSKI & $\begin{array}{l}\text { Moderate to good } \\
\text { response }\end{array}$ \\
\hline $30 / \mathbf{F}$ & Lt.thigh & - & Kolkata & $2^{\text {nd }}$ & $1^{\text {st }}$ & $1^{\text {st }}$ & oralSSKI & Complete cure \\
\hline $6.5 / \mathrm{F}$ & $\begin{array}{l}\text { buttock \& } \\
\text { loin }\end{array}$ & - & Kolkata & $2^{\text {nd }}$ & ND & $3^{\mathrm{rd}}$ & oralSSKI & Good response \\
\hline $45 / F$ & Lt. Arm & Mycetoma & Hoogly & $1^{\text {st }}$ & $1^{\text {st }}(?)$ & NG & oralSSKI & $\begin{array}{l}\text { Moderate to good } \\
\text { response }\end{array}$ \\
\hline $40 / F$ & $\begin{array}{l}\text { Rt. } \\
\text { Buttock \& } \\
\text { Thigh }\end{array}$ & $\begin{array}{c}\text { Cold } \\
\text { abscess }\end{array}$ & $\begin{array}{l}\text { Tripura, } \\
\text { Agartata }\end{array}$ & $2^{\text {nd }}$ & $2^{\text {nd }}$ & $3^{\text {rd }}$ & oralSSKI & Good response \\
\hline $3 / \mathrm{F}$ & $\begin{array}{l}\text { Rt. } \\
\text { Buttock }\end{array}$ & $\begin{array}{l}\text { Soft tissue } \\
\text { tumor }\end{array}$ & Malda & $1^{\mathrm{st}}$ & ND & $1^{\text {st }}$ & oralSSKI & $\begin{array}{l}\text { Swelling } \\
\text { disappeared }\end{array}$ \\
\hline $5 / \mathbf{M}$ & Lt. Thigh & $\begin{array}{l}\text { Lupus } \\
\text { vulgaris }\end{array}$ & Kolkata & $1^{\mathrm{st}}$ & $2^{\text {nd }}$ & NG & oralSSKI & $\begin{array}{l}\text { Moderate to good } \\
\text { response }\end{array}$ \\
\hline
\end{tabular}

Figure.1 Patients of different age groups presented with subcuteneous swellings at different sites

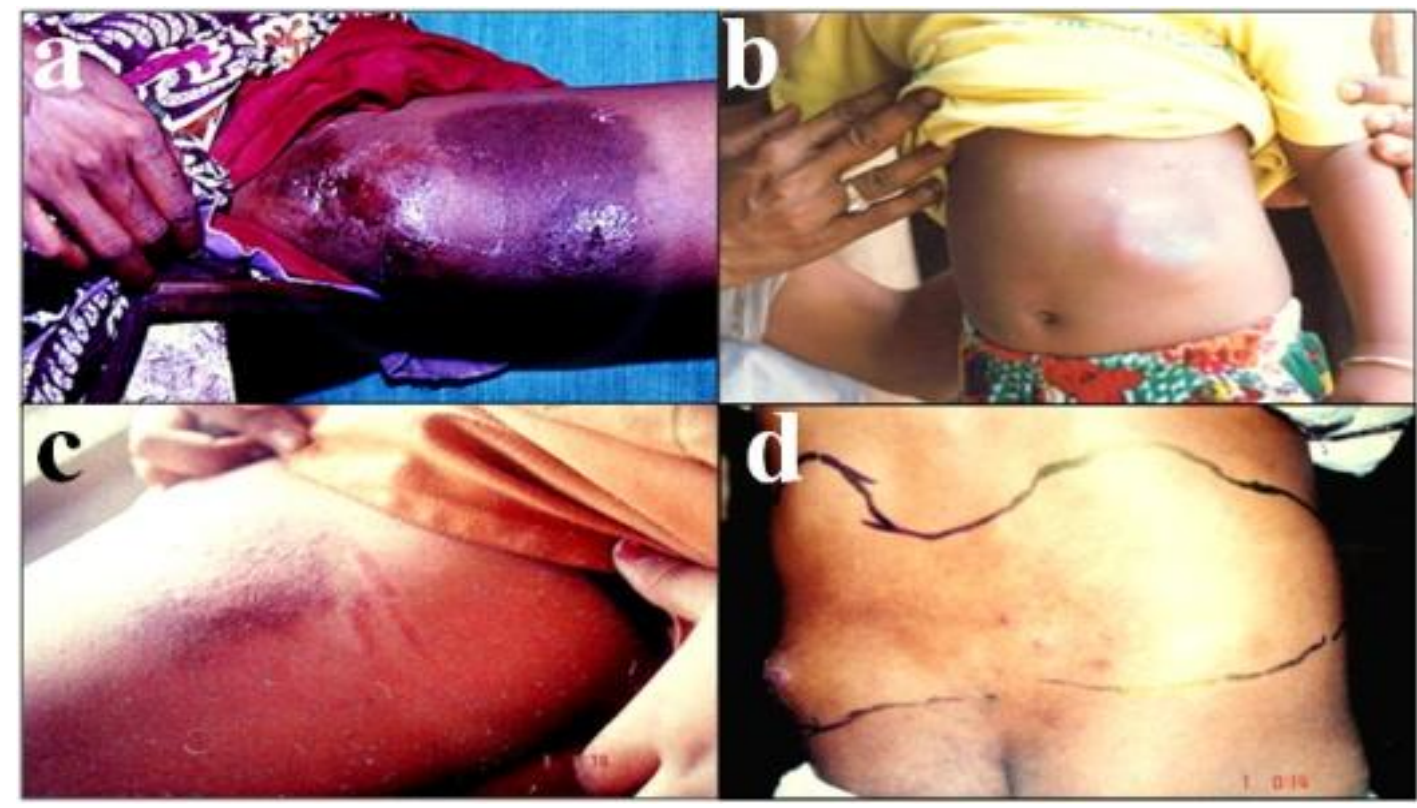


Figure.2

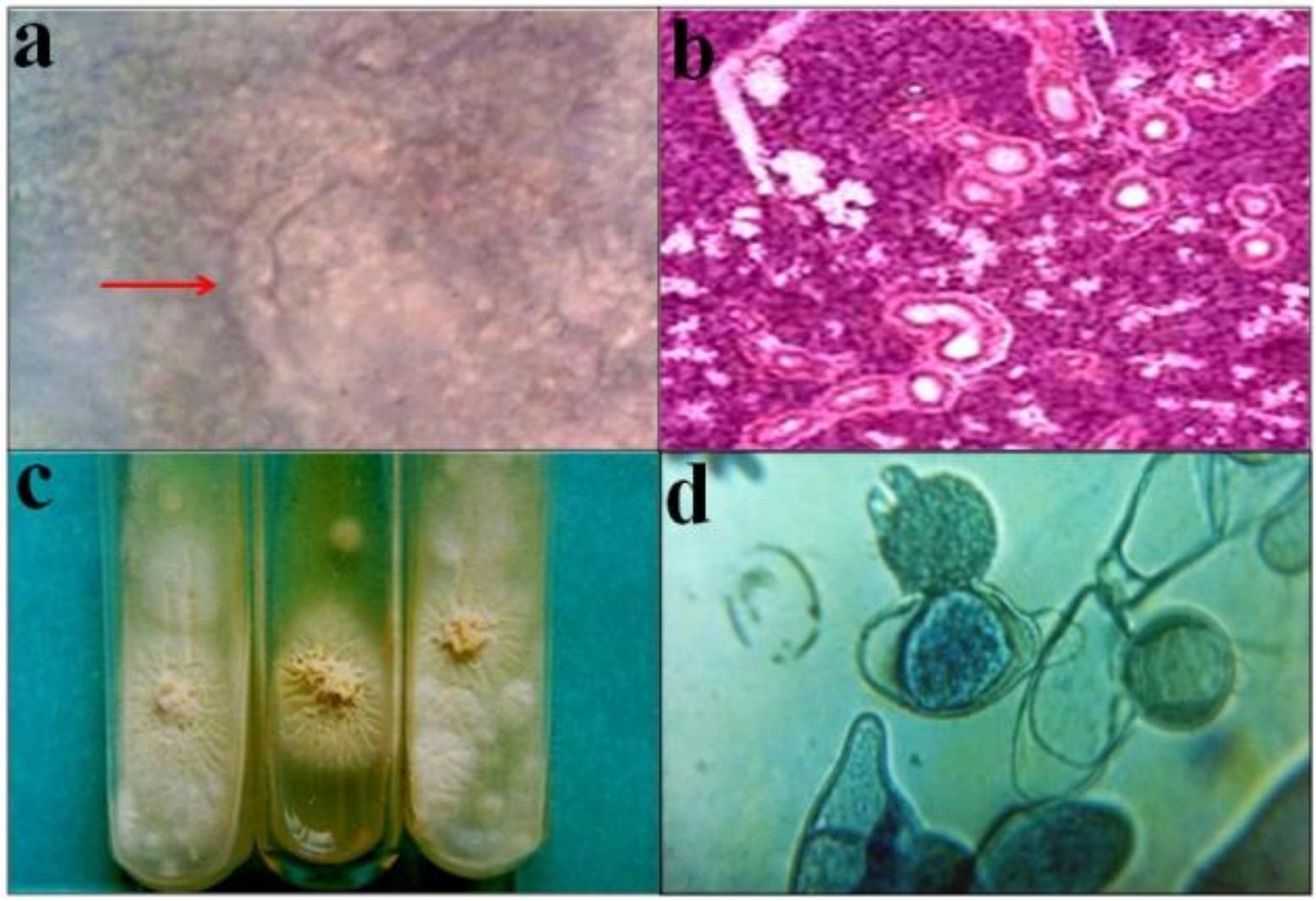

a. broad hyphea seen in $\mathrm{KOH}$ mount.(40x10)

b. fungal elements consistent with zygomycosis, and structures showing Splendore-Hoeppli bodies.(40x10)

c. On Sabouraud agar, colonies had a waxy, yellowish-to-gray appearance with many radial folds.

d. On microscopic examination of LPCB smear, B. ranarum identified by characteristically paired beaked zygospores.(40x10)

It may have a smooth, rounded edge where the fingers can be insinuated underneath and the swelling lifted off the underlying tissues, the insinuation sign. ${ }^{[5]}$ The overlying skin may be normal, pigmented, scaly, and edematous. Ulceration and regional lymphadenopathy are rare. Deeper extension into muscle and viscera are possible complications. ${ }^{[6]}$

$B$ ranarum is a saprophytic fungi and is present in soil, decaying vegetable matter, and the intestines of amphibians, reptiles, fish and insectivorous bats. [7] Subcutaneous basidiobolomycosis is endemic to rural areas of the tropical and subtropical zone, particularly Indonesia, Burma, India, particularly South India, and sub-Saharan Africa. ${ }^{[8}$ Other than subcuteneous basidiobolomycosis gastrointestinal and disseminated basidiobolomycosis also recenty reported. ${ }^{[3],[4]}$ The first four human cases were reported in 1956 from Indonesia. ${ }^{[9]}$ In Africa, the condition was first reported in1961, from Uganda where it appears to be widespread. ${ }^{[10]}$ Subsequently, reports were received from Sudan, Kenya, Cameroons and Nigeria. Mugerwa reported 80 cases of 
subcutaneous phycomycosis infection in Uganda seen between 1967 and $1974.76 \%$ of the patients were under 10 years of age, and $88 \%$ under 20 years of age. ${ }^{[11]}$ Mugerwa suggested that the use of 'toilet leaves' to clean after defecation might explain the observed distribution of lesions and source of infection. The precise mode of acquisition of $B$ ranarum is poorly understood but is thought to be acquired through skin after an insect bite, a scratch or minor cut. It may be picked up from decaying leaves used for cleansing after bowel movement, resulting in direct inoculation in the perineum (Mugerwa, 1976). ${ }^{[1]}$

In our region it is most probably acquired due to sitting of naked children on earthen floor mixed with insect drooping. ${ }^{[12]}$ Iatrogenic infection has also been reported. ${ }^{[8]}$ Differential diagnosis of subcuteneous basidiobolomycosis includes soft tissue tumors, lymphoma, lupus vulgaris, scrofuloderma, lymphogranuloma venerum , mycetoma, buruli ulcer, filerial elephantiasis. ${ }^{[7],[14],[15]}$ So, age and site of involvement without any signs of systemic invovement should lead to a high degree suspicion of subsuteneous basidiobolomycosis.

Males are more frequently affected than females in most cases, but in our study there was female preponderance. In our study two female patients presented swelling at two unusal sites, one on left upper abdomen and other on left arm. Similar condition was reported by Sing R et al where 11 year female child presented with nasal mass with extradural extension. ${ }^{[13]}$ Definitive diagnosis is based on $\mathrm{KOH}$ microscopy, culture and histopathology though repeated attempt may require to come to a diagnosis. In addition to culture, infection with $B$. ranarum may be diagnosed by an immunodiffusion test ${ }^{[13]}$. This test is useful for monitoring infected patients and in making a diagnosis of disease even in the absence of culture. But it is not routinely available. Unfortunately unlike much other fungal disease no molecular tests are available to confirm basidiobolus infection. So diagnosis may be missed without high degree clinical suspicion. Only $50 \%$ are diagnosed by single attempt $\mathrm{H} / \mathrm{P}$ examination or culture. ${ }^{[12]}$ Lack of experience due to very rare disease posing problem to clinicians, pathologists and microbiologists. During collection of material by clinician focal granulomatous zone containing fungal bodies may be missed as investigation approaches towards tumor detection. Cut section of broad fungal bodies may be missed. Repeated cut sections may have to look to conclude the diagnosis otherwise fungal structure may mimic with blood vessels or lymphatic vessels. Histopathologically it typically presents with few fungal bodies, little inflammatory cells and huge proliferation of connective tissue. This may be due to exoantigen or protease triggering connective tissue proliferation. This may the reason sometimes basidiobolomycosis misdiagnosed as connective tissue tumor. However this sarcoma never invade blood vessel. In our study we have found three cases which misdiagnosed as rabdomyosarcoma at first, later growth of $B$ ranarum was found by repeated attempt. Though one child was lost on follow up and later found to be treated with exicision and chemotherapy. It could be responded with itraconazole even it was given prophylactically along with cytotoxic chemotherapy.

Before culture tissue should be minced aseptically. During mincing excess cut may damage fungi, if multiple pieces are not inoculated in several tubes growth may be missed. So cultural demonstration is difficult, though positive culture almost always confirm the diagnosis but negative growth can't rule 
out. Sometimes therapeutic resolution with saturated solution of oral pottassium iodide resolves the diagnostic dilemma of differential diagnosis of subcuteneous basidiobolomycosis. But the solution must be saturated which is not commercially readily available. It has to be prepared by experienced pharmacist. Here all patients were treated with saturated solution of oral potassium iodide and responded very well. Though the precise mechanism of $\mathrm{KI}$ is unknown. It is thought that it acts as a immunomodulator. The direct action of KI on the fungus has been denied and the activation of macrophages by iodine has now been assumed to be responsible for the healing effect. ${ }^{[16]}$ The spontaneous healing and the variability of the clinical presentation in the disease have strengthened the idea that KI rather interacts with the immune response of the host. ${ }^{[17]} \mathrm{A}$ suggested dose of potassium iodide for children is $30 \mathrm{mg} / \mathrm{kg} /$ day for many months. Our patient were treated with oral supersaturated solution of potassium iodide starting at five drops thrice daily which was increased by one drop daily to a maximum of forty drops per day. Other than SSKI effective treatments with ketoconazole, itraconazole,fluconazole, and co-trimoxazole also reported. ${ }^{[8]}$

In conclusion, these cases may be the tip of the iceberg. We may be missed some cases due to poor clinical suspicion and lack of experience. Here we report this study to increase awareness of a disfiguring condition which is treatable but, if not correctly diagnosed, could result in inappropriate interventions such as amputation and chemotherapy. On review wrongful diagnosis of rabdomyosarcoma without evidence of vascular invasion or metastasis was concluded in one defaulter child of this study due to poor response with KI solution at mucolytic concentration and failure of mycological confirmation in single chance. This could be a take home message for clinicians before labeling a benign condition as highly malignant one.

\section{References}

1.Ribes JA, Vanover-Sams CL, Baker DJ. Zygomycetes in human disease. Clin Microbiol Rev 2000; 13: 236-301

2.Maiti PK, Bandyopadhyay D. A case of entomopthoromycosis refractory to conventional therapy. Indian J Med Microbiol. 1999; 17: 150-1.

3.Khan ZU, Khoursheed M, Makar R, AlWaheeb S, Al-Bader I, Al-Muzaini A, et al. Basidiobolus ranarum as an etiologic agent of gastrointestinal zygomycosis. J Clin Microbiol 2001;39: 2360-3.

4.Van den Berk GE, Noorduyn LA, van Ketel $\mathrm{RJ}$, van Leeuwen J, Bemelman WA, Prins JM. A fatal pseudo-tumour: Disseminated basidiobolomycosis. BMC Infect Dis 2006; 6: 140.

5. Arora P, Sardana K, Bansal S, Garg VK, Rao S. Entomophthoromycosis (basidiobolomycosis) presenting with "saxophone" penis and responding to potassium iodide. Indian J Dermatol Venereol Leprol 2015; 81: 616-18

6. Ramesh V, Seshadri D, Ramam M, Habib ST. Deep fungal infections. In: Sacchidanand S, editor. IADVL Textbook of Dermatology. 4th ed. Mumbai: Bhalani Publishing House; 2015. p. 534-38.

7. Gugnani HC. A review of zygomycosis due to Basidiobolus ranarum. Eur. J. Epidemiol. 1999 Nov; 15(10):923-929.

8.Sackey A, Ghartey N, Gyasi R. Subcutaneous basidiobolomycosis: A Case Report. Ghana Med J. 2017;51(1):43-46.

9.Joe LK, Eng, Pohan A, Van Der Muillen $\mathrm{H}$,Emmons CW. Basidiobolus ranarum as a cause of subcutaneous mycosis in 
Indonesia. AMA Arch Dermatol. 1956 Oct; 74(4): 378-83.

10.Burkitt DP, Wilson AMM, Jelliffe DB. Subcutaneous phycomycosis: A review of 31 cases seen in Uganda. Br Med J. 1964 Jun; 1(5399): 1669-1672.

11. Mugerwa JW. Subcutaneous phycomycosis in Uganda. $\mathrm{Br} \mathrm{J}$ Dermatol. 1976 May; 94(5):539-441.

12. Maiti PK, Bose R, Bandyopadhyay S, Bhattacharya S, Dey JB, Ray A. Entomophthoromycosis in South Bengal (Eastern India) : a 9 years study. Indian J Pathol Microbiol. 2004; 47: 295-97.

13. Singh R, Xess I, Ramavat AS, Arora R. Basidiobolomycosis: A rare case report. Indian J Med Microbiol. 2008 Jul-Sep; 26(3): 265-7.

14.Gummadi GK, Pai BS, Nayak UK,
Prakash PY, Pai K. Basidiobolomycosis mistaken for cutaneous tuberculosis. Indian J Dermatol Venereol Leprol 2019; 85: 236.

15.Thotan SP, Kumar V, Gupta A, Mallya A, Rao $S$. Subcutaneous phycomycosis-fungal infection mimicking a soft tissue tumor: a case report and review of literature. J Trop Pediatr. 2010 Feb; 56(1):65-6.

16. Hassan I, Keen A. Potassium iodide in dermatology. Indian J Dermatol Venereol Leprol. 2012; 78: 390-3.

17. Maiti PK, Das S,Ghosh T, Dey R. Effects of Potassium Iodide on Low Avid Immunological Reactions: Probable Mechanism of Action on Selective Fungal Infections Ann Med Health Sci Res. 2013 Jul-Sep; 3(3): 397-401

\section{How to cite this article:}

Pal Nupur, Pal Sangeeta, Pal Sayan, Kalidas Rit, Maiti K. Prasanta and Chatterjee Gobinda. 2019. Diagnostic Dilemma of Subcuteneous Basidiobolomycosis: A Clinicomycological Study. Int.J.Curr.Microbiol.App.Sci. 8(06): 2181-2188. doi: https://doi.org/10.20546/ijcmas.2019.806.259 